\title{
USE OF THE LIDAR COMBINED FOREST INVENTORY IN THE ESTIMATION OF FELLING SITE STOCKS
}

\author{
Antons Seleznovs, Dagnis Dubrovskis, Salvis Dagis, Ingus Smits, Raivis Baltmanis \\ Latvia University of Life Sciences and Technologies, Latvia \\ anton.se1008@gmail.com
}

\begin{abstract}
Precision of the forest inventory still is one of the most important problems in the forestry nowadays. The aim of this research was to estimate the results of the combined forest inventory (CFI), using high spatial resolution aerial images in the planned areas of clear-cuts, comparing the results with the calipering and production files of harvesters. Testing of algorithms showed considerable difference in results between the CFI, forest inventory data and harvester production data. CFI results and production data had a close correlation with $\mathrm{R}^{2}=0.83$. Comparing CFI calculated growing stock with production data, the average relative error amounted to $10.7 \%$, which means the possibility for integration of these results into the forest inventory system. Comparing to CFI, there is a weak correlation between forest inventory and production data with $\mathrm{R}^{2}=0.34$. The results indicate that LiDAR CFI technology can be used in the forecasting of the forest management, offering precise information about potential amount and economic value of assortments.
\end{abstract}

Key words: combined forest inventory, LiDAR, forest management, growing stock volume, harvester production data.

\section{Introduction}

One of the most important problems in forest inventory is the precision of the data about growing stock and making a forecast about the value and amount of assortments. Due to development of the digital technologies, one of the fields for use of them became forestry. Already in 1944 Finnish scientists started the flights for preparing of the forest digital surfaces with the aim to make for them forest management plans (Vastaranta et al., 2015). After 1997, there were studies of using LiDAR (Light identification and ranging) technology in the forest management. The studies were connected with the mean diameter at breast height, stand structural complexity and identification of tree species. Numerous studies showed that forest inventory variables can be measured and registered precisely using LiDAR data (Treitz et al., 2012).

Using of LiDAR technology in Latvia began in 2007 when a group of the scientists from Latvia University of Life Sciences and Technologies started researches for the possibility of LiDAR data integration into forest inventory and forest management planning. In the year 2010 in cooperation with the company 'Metrum' the method for integration of LiDAR data into forest management development started. The method itself contains NIR (near infrared) pictures and LiDAR data, according to this information the centers of the sample trees, which are the part of micro forest stands are defined. Based on this method a research about the possibility of tree species recognition, using LiDAR data was provided (Priedītis, 2013). Positive results of the researches caused a necessity of broader study in the field of LiDAR technology, trying to integrate it in the estimation of growing stock in forests. One of the topical problems in Latvia is the usage of the forest inventory methods, based on estimation by sight (Grīnvalds, 2016). Generally, the same problem was matched also in other countries. The main reasons for this inaccuracy are the subjective estimation of the evaluators as well as a number of measuring points during the forest inventory. The estimation of the mean height using LiDAR technology showed already precise results, comparing the result of laser scanning to the measurements in sample plots, but the recognition of mean diameter at breast height is still difficult because of a high tree density, which can disturb the shooting of laser signal (Będkowski, Brach, \& Banaszczak, 2011). Due to growing diversity of forest stands structure, traditional yield tables are getting unreliable for the forest inventory. However, the traditional mensuration by using of yield tables has lower costs, but is not deliberated for uneven-aged forest stands. Airborne laser scanning (ALS) is a good way for solution of uneven-aged forests' management problem, collecting accurate characteristics of the three dimensional structure of a forest in a short time, deriving tree and stand characteristics (Kulla, Sačkov, \& Juriš, 2016). Although the majority of forest stands in Latvia are even-aged structure, especially within state owned forests, the technology can be used also for the monocultures and even-aged mixed forest stands, forecasting the growth of individual trees and stands based on regular LiDAR measurements, making the estimation of their economic value (Tomppo et al., 2017).

The main objective of this research is to estimate and compare the taxation data such as growing stock, basal area, mean height and mean diameter at breast height obtained from LiDAR CFI with inventory data based on the sight estimation and growing stock volume additionally to harvester production data. 


\section{Materials and Methods}

Study area

The areas were located in state-owned forests of JSC 'Latvian State forests', in the northwestern part of Latvia (Fig. 1). For the needs of research, 495 cutting areas which contained the production files of harvester were selected. Study contains information for the cutting areas in the period from 2014 to 2017. Among all areas coniferous trees, which were selected into four groups dominated: Scotch pine (Pinus sylvestris L.) monocultures, Norway spruce (Picea abies L.) monocultures, Scotch pine and Norway spruce mixed forest stands and Pine, Norway spruce and Silver birch (Betula pendula Roth.) mixed forest stands.

\section{LiDAR CFI technology}

The method presents two types of data: LiDAR and NIR (near infrared) photos. Basic data are used for identifying sample trees and their specific characteristics. The main aspect for tree identifying is NIR photo, according to local maximums of spectrum. All tree centers have a list of parameters based on LiDAR and NIR data (Table 1)

Calculated set of parameters is a basis for a next CFI data analysis. LiDAR data is saved in a '.las' format. The LiDAR data can be processed after noise removal. For this aim, Gauss matrix was used. According to this matrix, the highest points of trees and distance to the terrain, registered as a tree height are calculated. To make a tree model, it is necessary to find LiDAR points that belong to a specific tree. During the tree model creation the points within a radius of $6 \mathrm{~m}$ from crown top were used. In case when the points are under the top of tree, they belong to a specific tree. For feasible tree identification NIR data were used. Main impact factors for a quality of NIR data are quality of aero photo and size of pixel. Process of tree identification contains preparing and processing of photo and promulgation of results. To complete this task an aero photo is cut into smaller photos, which have strict geographical binding. The sizes of the photos were based on power of number 2. Using of Fourier transform fades in a texture and makes a legible model of tree stand. As a result, there is information based on LiDAR and photo data about sample tree location and determination of micro forest stands borders within the quarters. Creation of small sized areas assumed the identification of tree species and tree center location. Using a cluster algorithm, micro forest stands are divided into the groups with the similar inventory data description. Some of inventory data such as an age of tree stand, type of forest, sample plot data are imported to the system for a better calibration of LiDAR data. The rest of inventory data is calculated in following sequence, using LiDAR and measured sample plot data: mean height, tree species structure, growing stock, mean diameter at breast height, basal area of forest stand and separate species (Goodbody et al., 2017).

Sample plots

Allocation of sample plots is based on micro forest stand areas. In the research, the sample plots were analyzed, where the clear-cuts were planned. Total number of sample plots increased to 495. Comparison of field inventory data with LiDAR CFI contained information about tree species, mean height, mean diameter at breast height, basal area and growing stock volume. Data sources were geographically connected. Sample plots were located within one micro forest stand and did not contain the trees from neighbor areas.

Harvester production data

Data from harvester production (PRD) was saved as '.prd' files and is used for data calibration. Data of clear-cuts was chosen, because for an analysis of

Primary processing of LiDAR and NIR data

Table 1

\begin{tabular}{|l|l|l|}
\hline \multicolumn{1}{|c|}{ Group of data } & \multicolumn{1}{|c|}{ Name of parameter } & \multicolumn{1}{c|}{ Description } \\
\hline \multirow{4}{*}{ IIR } & Position of sample tree center & \multicolumn{1}{c|}{$\times$} \\
\cline { 2 - 3 } & h, e, i & $\begin{array}{l}\text { Texture indicators, defined in accepted radius } \\
\text { around a tree center }\end{array}$ \\
\cline { 2 - 3 } & nir & Value of NIR channel \\
\hline \multirow{4}{*}{ LiDAR } & Position of sample tree center & \multicolumn{1}{|c|}{$\times$} \\
\cline { 2 - 3 } & h & Sample tree height \\
\cline { 2 - 3 } & Slope & Slope coefficient of crown top \\
\cline { 2 - 3 } & z_avg, z_sigma & Center indicators of foliage mass \\
\cline { 2 - 3 } & evp, vp, vpa & Dimension of tree crowns \\
\cline { 2 - 3 } & htc, ntr, vpa & Neighboring tree interaction indicators \\
\cline { 2 - 3 } & histogram & Tree point vertical bar chart \\
\hline
\end{tabular}




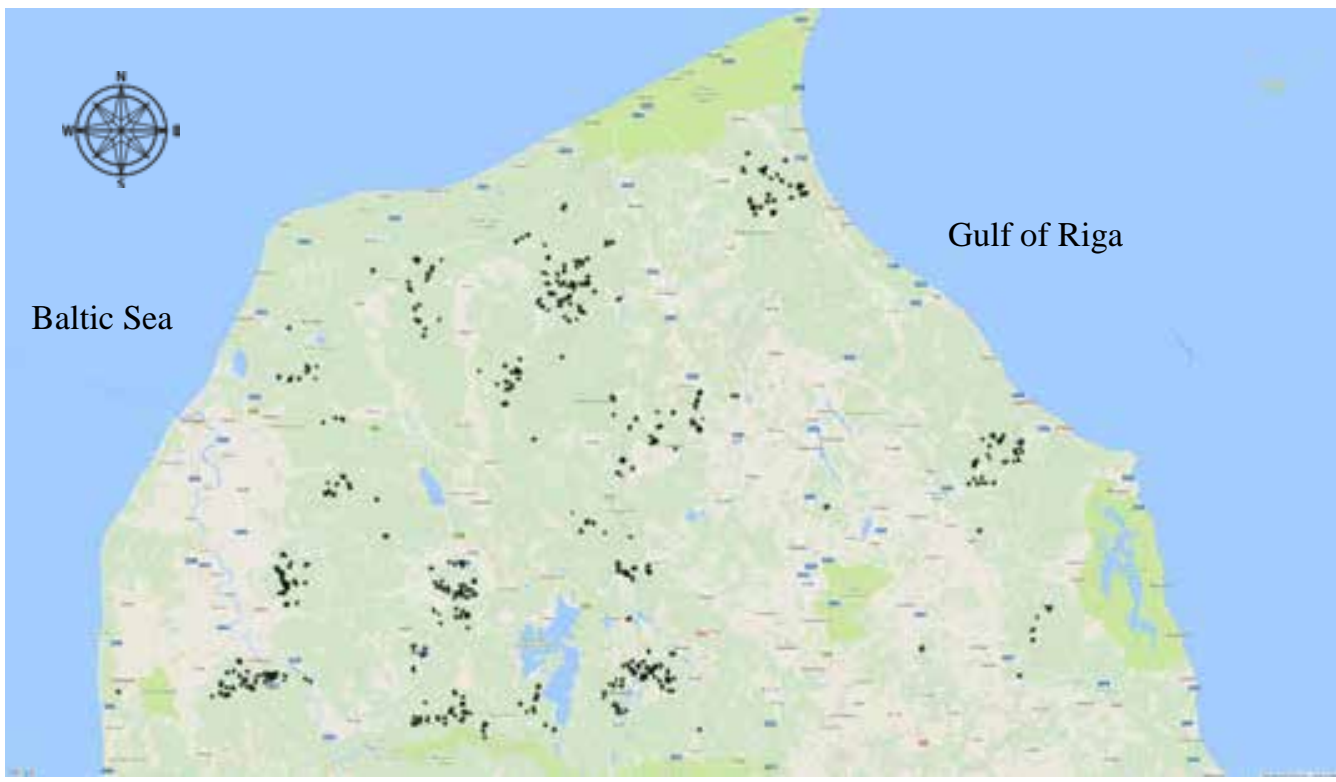

Figure 1. Allocation of sample plots with planned clear-cuts marked with the black points.

thinning cuts additional remote sensing control would be necessary. Summarizing the information about prepared assortments, calculation of species structure and growing stock volume is possible. Calibration files contained only the areas, which were within one plot and did not contain the information from other plots or considerable differences in inventory data. During the research, production data was used for calibration of growing stock algorithms. Primarily LiDAR and NIR data were uploaded, which were used for an identification of sample trees and their inventory data. Additionally, '.prd' files of harvester were uploaded. Growing stock volume calibration was done in the program R. After successful comparison of ‘.prd' and remote sensing data, information integrated to areas, where the result of tree species calculation was the same for two methods.

\section{Data processing}

During the research, the LiDAR and PRD data were processed. With the help of a statistics program $\mathrm{R}$, a regression analysis for growing stock volume, using one factor and multi factor analysis was completed. The results showed in the graphics, brought the information about coefficient of determination. Analysis of height and diameter at breast height was calculated from LiDAR CFI data completed in Microsoft Excel program, using a regression analysis with a confidence level of $95 \%$.

\section{Results and Discussion}

Based on comparison with the field inventory and PRD data, the results of growing stock volume for LiDAR CFI demonstrated different correlation. Previous methods allowed to compare a growing stock volume calculated from the field data to PRD production data. For the first time a vast use of LiDAR CFI technology in the research has been done in Latvia. The research compares data from 495 clear-cuts areas, containing the information about both field inventory data and PRD production data as well as LiDAR data. Figure 2 demonstrates the result of comparison of on field inventory based growing stock volume results to PRD files.

The result shows that a determination coefficient is low $-\mathrm{R}^{2}=0.34(\mathrm{p}<0.01)$. Reason for weak correlation is an inaccuracy in field data collection and calculation. Provided by a person, results can contain a subjective estimation of growing stock volume, making a considerable difference to PRD data estimation. Considerably better result demonstrated a comparison of PRD and LiDAR CFI result given in Figure 3.

According to growing stock volume comparison, obvious is a strong correlation of LiDAR CFI to PRD data. Result is important for a forest management planning, because of high precise growing volume stock calculation using LiDAR CFI methods. Comparing field inventory data to LiDAR CFI and PRD determination coefficients declared a value of 0.37 and $0.34(\mathrm{p}<0.01)$ correspondingly. The main reason for a weak correlation are mistakes in the field inventory because of subjective estimation and random analysis of tree stands, using outdated reduction coefficients for tree height based on mean calculation data, ignoring a diversity of stem structure (Sedliak, Sačkov, \& Kulla, 2017). LiDAR technology completes the analysis of the whole stem, disturbing aspects are only high density in the forest stand and second storey, which does not allow to find a terrain. 


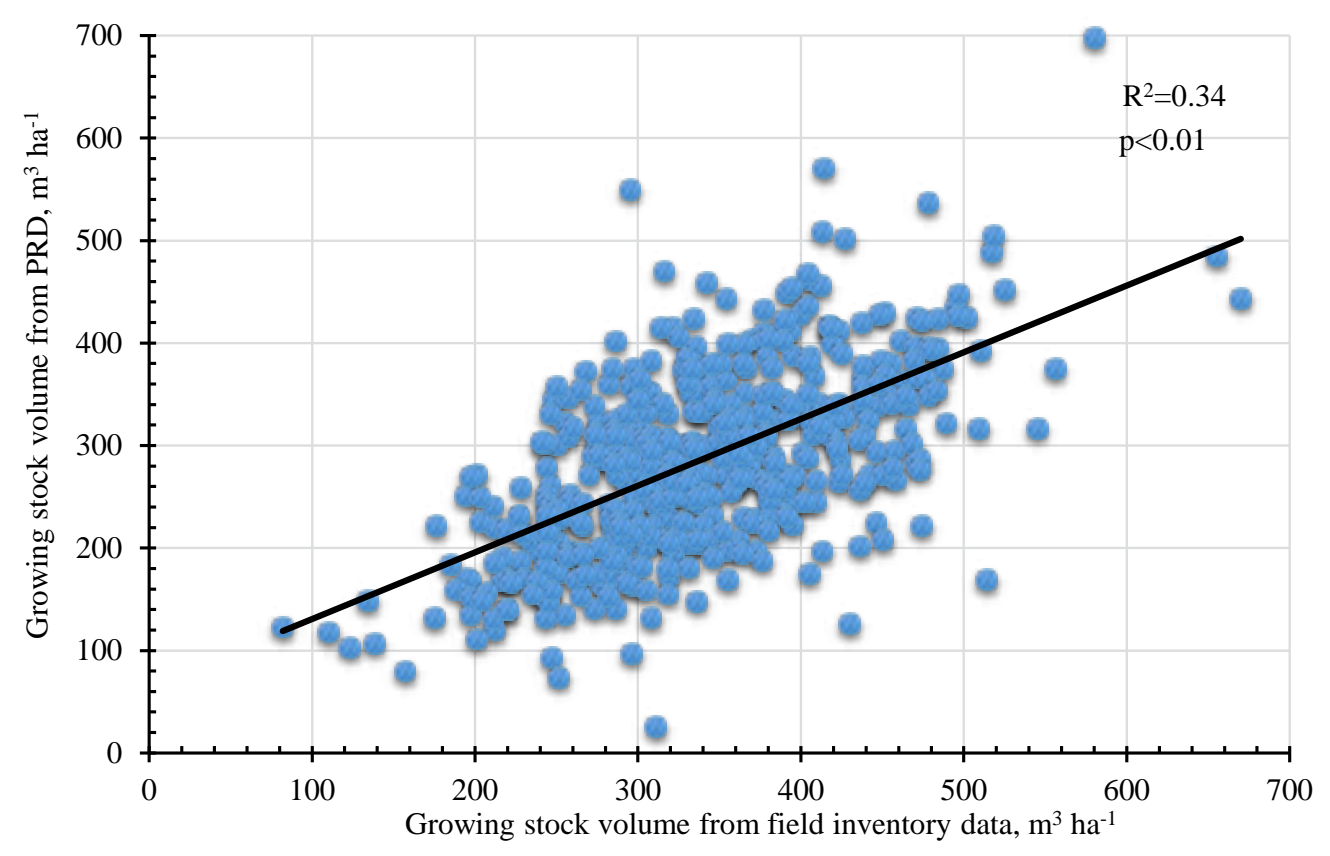

Figure 2. Comparison of field inventory data to PRD file growing stock volume data.

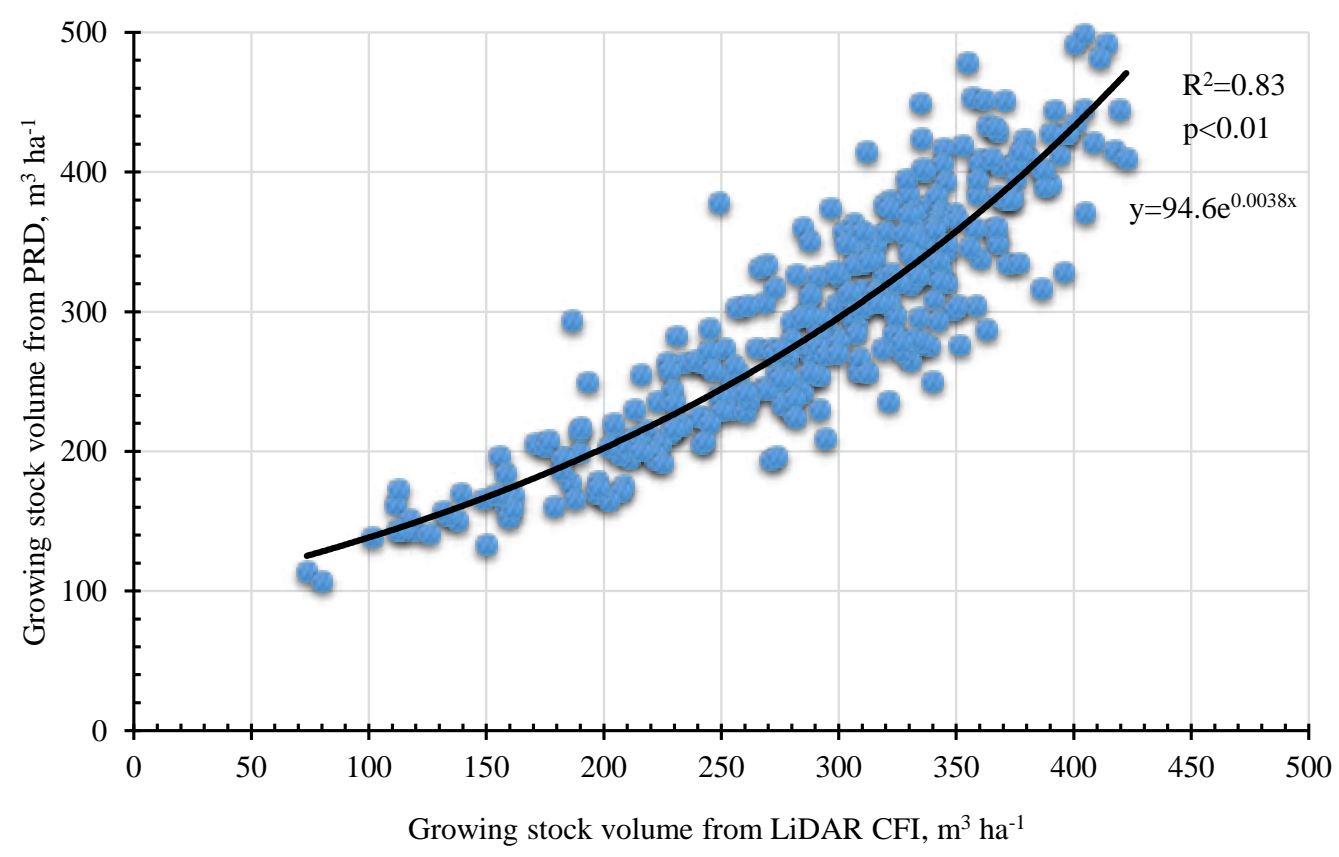

Figure 3. Comparison of CFI data to PRD growing stock volume data.

Use of LiDAR technology in broadleaved forests can be provided in one-storey stands with no foliation, otherwise it is not possible to use the interpretation algorithm processing the data (Sabol, Prochazka, \& Patočka, 2016). In case of our study in plots dominate conifer tree species and second storey met singly, that is why the results of LiDAR could be integrated to the system easily, getting the precise data about growing stock volume and tree height. Positive perspective of an integration of LiDAR CFI technology demonstrates also correlation with PRD production data -0.83 . In practice it means that $83 \%$ of data variability is described by the model. An average relative error value of $10.7 \%$ brings a possibility to integrate the results into the forest inventory system. Although PRD data demonstrates the result from prepared assortments, describing LiDAR CFI as a reliable method for forest owner to predict the incomes from 


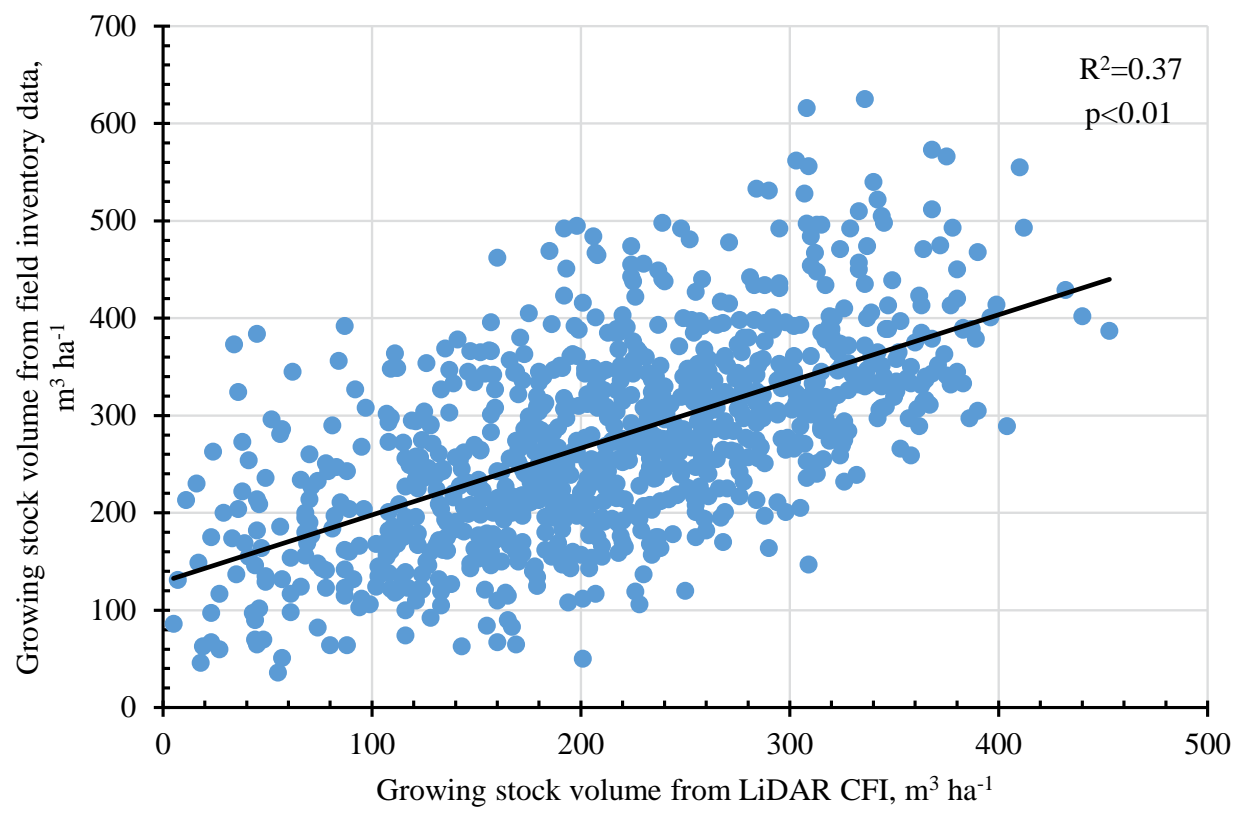

Figure 4. Comparison of LiDAR CFI data to field inventory growing stock volume data.

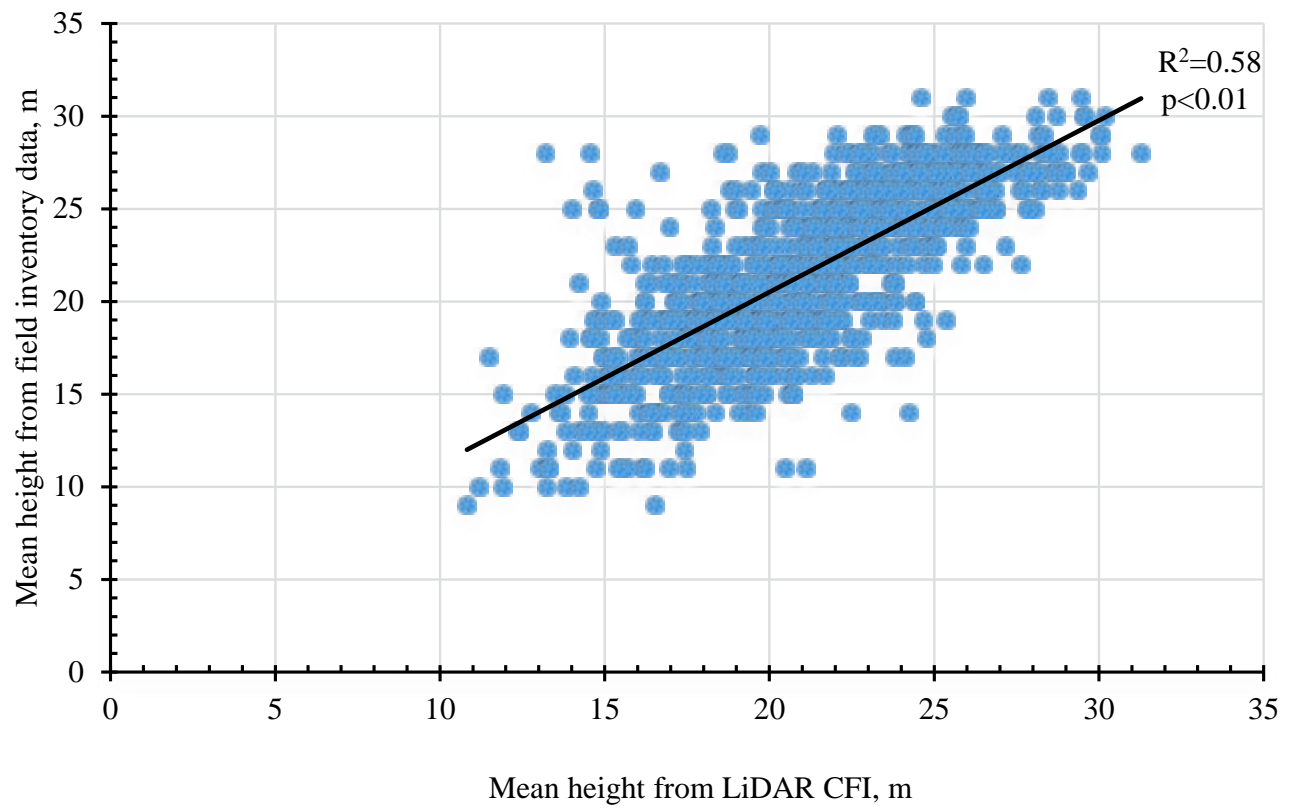

Figure 5. Comparison of LiDAR CFI data to field inventory mean height data.

the cuttings, it is still necessary to pay attention to the inaccuracy in forest inventory data. Comparing LiDAR CFI calculated data of height and diameter at breast height to forest taxation data, the result of height demonstrated better correlation than diameter. The value of determination coefficient for mean height linear model is $\mathrm{R}^{2}=0.58(\mathrm{p}<0.01)$.

This result is the best of all comparisons between LiDAR CFI data and taxation data. Main errors in this case are the errors in taxation data acquisition and mistakes in the identification of height in the second storey using LiDAR CFI data. Comparison of LiDAR CFI data diameter at breast height to forest inventory breast height demonstrated a low determination coefficient $-\mathrm{R}^{2}=0.37$ (Figure 6). Based on the data of diameter at breast height, also basal area was calculated and brought the result of $\mathrm{R}^{2}=0.19$. The reason is the same as for other taxation data - incompleteness in taxation data. Despite different determination coefficient values, $\mathrm{p}$-value in all comparisons is less 


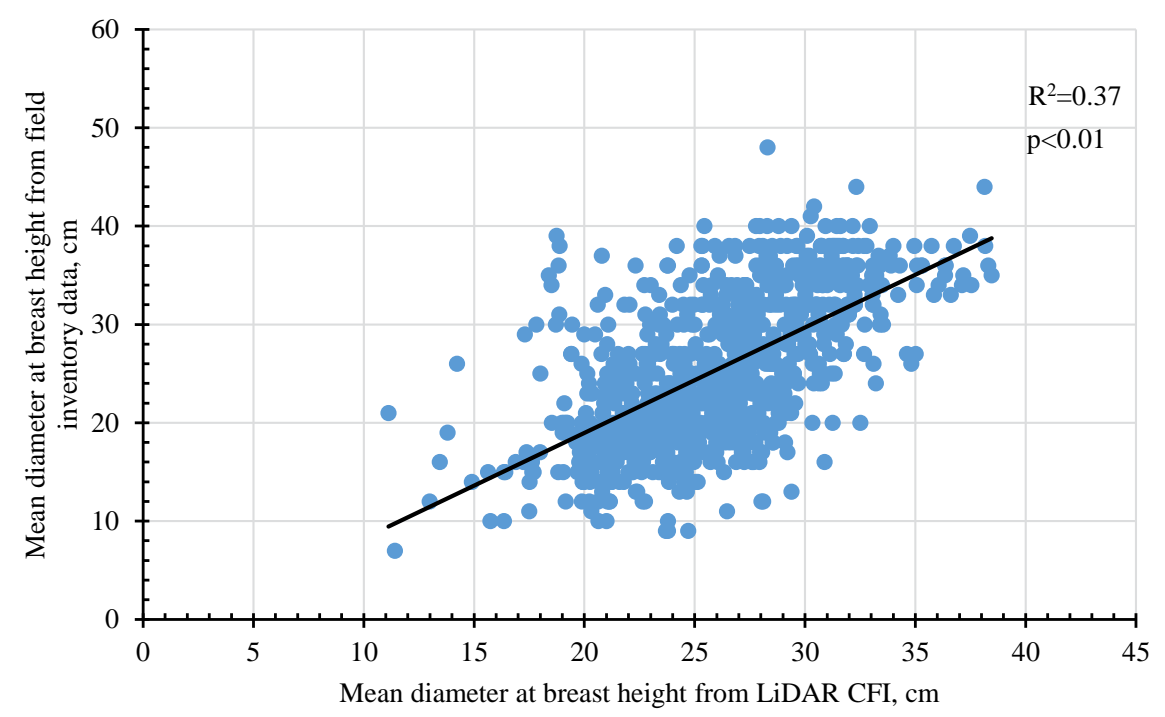

Figure 6. Comparison of LiDAR CFI data to field inventory mean diameter at breast height data.

than 0.01 , showing a considerable significance of the factor. Reason is the comparison of the same taxation data, but from different data sources.

For a thorough check of LiDAR CFI, calculated data needed precise report data. The comparison with forest field inventory demonstrates a low determination coefficient showing disadvantages of current taxation information. Solution of this problem is topical for European researchers, who indicate on necessity to continue the researches on a breast height distribution in the forest stands with the different structures. These researches should contain information about different tree species and investigate the interrelations between tree stand age, height, canopy density and diameter at breast height. Successful researches in this area will modify the forecasting model of assortments outcome (Apostol et al., 2016).

\section{Conclusions}

1. Comparison of LiDAR CFI data with forest taxation data demonstrated a weak correlation, except the tree height parameter $\left(\mathrm{R}^{2}=0.58\right)$.

2. The main reason for a weak correlation and low determination coefficient results is incompleteness in forest taxation unplaited by subjective estimation of taxation data in forest stands.

3. LiDAR CFI estimated growing stock volume showed a high determination coefficient to PRD file results $\left(\mathrm{R}^{2}=0.83\right)$.

4. Topical for forestry are the studies about interrelations between the tree stand height, age, canopy density and diameter at breast height and the different tree species structure to create a forecasting model of assortments outcome.

\section{References}

1. Apostol, B., Lorent, A., Petrila, M., Gancz, V., \& Badea, O. (2016). Height extraction and volume estimation based on fusion airborne LiDAR data and terrestrial measurements for a Norway Spruce (Picea abies L.) test site in Romania. Not. Bot. Horti. Agrobo. 44(1), 313-323. DOI: 10.15835/nbha44110155.

2. Będkowski, K., Brach, M., \& Banaszczak, P. (2011). Sezonowa zmienność rozkładu chmury punktów skanowania laserowego $\mathrm{w}$ drzewostanach iglastych i jej związek z cechami taksacyjnymi drzewostanu (Seasonal variability of distribution of laser scanning point cloud in coniferous stands and its relationship with stand valuation characteristics). Sylwan. 155(11), 736-748. (in Polish).

3. Goodbody, T., Coops, N.C., Marshall, P.L., Tompalski, P., \& Crawford, P. (2017). Unmanned aerial systems for precision forest inventory purposes: A review and case study. The Forestry Chronicle. 93(1), 71-81. DOI: 10.5558/tfc2017-012.

4. Grīnvalds, A. (2016). Stratēgiskās un taktiskās plānošanas sasaistes pilnveidošana galvenajā cirtē (Improvement of linkage between strategic and tactical planning in the final felling). Doctoral dissertation, Latvia University of Agriculture, Jelgava, Latvia. (in Latvian).

5. Kulla, L., Sačkov, I., \& Juriš, M. (2016). Test of airborne laser scanning ability to refine and streamline growing stock estimations by yield tables in different stand structures. Lesn. Cas. For. J. 62, 39-47. DOI: 10.1515/forj-2016-0005. 
6. Priedītis, G. (2013). Aerofotogrāfiju un aerolāzerskenēšanas datu izmantošanas specifika mežu inventarizācijā (Aerial photography and airborne laser scanner data usage specifics in forest inventory). Doctoral dissertation, Latvia University of Agriculture, Jelgava, Latvia. (in Latvian).

7. Sabol, J., Prochazka, D., \& Patočka, Z. (2016). Development of models for forest variable estimation from airborne laser scanning data using an area-based approach at a plot level. Journal of Forest Science. 62(3), 137-142. DOI: $10.17221 / 73 / 2015-J F S$.

8. Sedliak, M., Sačkov, I., \& Kulla, L. (2017). Classification of tree species composition using a combination of multispectral imagery and airborne laser scanning data. Cent. Eur. For. J. 63, 1-9. DOI: 10.1515/forj2017-0002.

9. Tomppo, E., Kuusinen, N., Mäkisara, K., Katila, M., \& McRoberts, R.E. (2017). Effects of field plot configurations on the uncertainties of ALS-assisted forest resource estimates. Scandinavian Journal of Forest Research. 32(6), 488-500. DOI: 10.1080/02827581.2016.1259425.

10. Treitz, P., Lim, K., Woods, M., Pitt, D., Nesbitt, D., \& Etheridge, D. (2012). LiDAR sampling density for forest research inventories in Ontario, Canada. Remote Sens. 4, 830-848. DOI: 10.3390/rs4040830.

11. Vastaranta, M., Niemi, M., Wulder, M.A., White, J.C., Nurminen, K., Litkey, P. Honkavaara, E., Holopainen, M., \& Hyypä, J. (2015). Forest stand age classification using time series of photogrammetrically derived digital surface models. Scandinavian Journal of Forest Research. 31(2), 194-205. DOI: 10.1080/02827581.2015.1060256. 